\title{
Revisiting Amit and Zott's model of value creation sources: The SymBelt Customer Center case
}

\author{
Niklas Johansson ${ }^{1}$ and Ulrika Mollstedt ${ }^{1}$ \\ ${ }^{1}$ Karlstad University, Department of Information Systems, Niklas.Johansson@kau.se \\ ${ }^{1}$ Ulrika.Mollstedt@kau.se
}

Received 30 June 2006; received in revised form 06 October 2006; accepted 30 October 2006

\begin{abstract}
Amit and Zott [2] recognized the importance of understanding value sources in electronic business (ebusiness). However, the concept of e-business is rather broad and therefore this paper suggests a more narrow focus on the value of complementary services. The reason for this approach is an ever-increasing importance for firms to provide complimentary services supporting products. Amit and Zott's [2] model of the sources of value creation in e-business includes four dimensions of value creation; efficiency, lock-in, complementarities and novelty. In contrast to Amit and Zott [2], we suggest that the four dimensions of the model should not only be used as value creation sources, but moreover as value evaluation dimensions.

The findings of this case study, where Metso Paper's Internet-based service (a complementary service) and some of their customers' perceptions of the service have been studied, show that the customers have used the services infrequently. This study also shows that in this specific business-to-business context, the characteristics of the product, which the Internet-based service supports, are vital. Therefore, we suggest a modification of Amit and Zott's [2] business model when used as a model for value evaluation of complementary services, to replace complementarities with nature of the core product.
\end{abstract}

Key words: Internet-based service, value evaluation, value creation 


\section{Introduction}

The importance of the value of products and services is crucial to firms providing all types of goods. Lately, the development of e-business has made it possible for firms to provide services in a way that was not possible earlier. As a result, customer service has become a "strategic imperative" for most firms [24]. Consequently, IS priorities are increasingly concerned with how IT can support customer service activities, activities which are dependent on employees and customers knowledge-sharing behavior [5]. This development has therefore lead to challenges for firms to provide valuable Internet-based services to their customers. Knowledge is said to be the foundation of a firm's competitive advantage and the most important driver of a firm's value [5]. In research, there has been a greater focus on value of Internet-based services in the business-to-consumer field than the business-to-business field. Therefore, it seems to be a knowledge gap for studying value of Internet-based services in a business-to-business context.

In this paper, we take a standpoint from Amit and Zott's [2] model of the sources of value creation in e-business. The main reason for this choice is that Metso Paper's initial idea behind the development of the Internet-based service, the SymBelt Customer Center (SCC), was coherent with the value dimensions in Amit and Zott's [2] model. The model, that includes four dimensions of value creation in e-business; efficiency, lock-in, complementarities and novelty, has been created from an analysis made in a business-to-consumer context. The model defines Internetbased services (named complementarities) as a source of value creation. However, due to a growing focus in general on complementarities, i.e. Internet-based services, we propose that sources of value creation in Internetbased services are vital to study alone and not only as a part of e-business.

This, somewhat different perspective, will have implications on this study's use of Amit and Zott's [2] model of value creation sources in e-business. Later on in this paper we will propose and argue for the necessity for a few changes of the model when studying evaluation of sources of value in Internet-based services in a business-to-business context. However, the fundamental ideas of Amit and Zott's [2] model will be used for evaluating the value of an Internet-based service in a business-to-business (B2B) context. The concept of B2B implies that two, rather than one; stakeholders' perspectives are necessary to study in order to understand value evaluation of Internet-based services. Therefore, in this study we will take a dyadic approach, meaning that perspectives, opinions and results from the supplier as well as the customer firms will be accentuated [7].

Another important standpoint we take in this study is that the model should not only be used as value creation sources [2], but moreover as value evaluation dimensions. User evaluation is an assessment made by a user, about certain qualities of an information system [15]. It is concerned with beliefs or attitudes towards an information system. Smithson and Hirscheim [30] state: "Evaluation means the assessment or appraisal of the value, worth or usefulness of an information system". Assessing use and understanding issues affecting adoption and user acceptance of technology-based systems and services is of imperative significance for organizations worldwide [9], [18], [24]. Brown [6] draws attention to the fact that many service providers have realized the importance to assess customers' perceptions of the service they offer. Likewise, Internet-based services also need to be assessed after being used in the right organizational context.

For approximately two years, from the spring of 2002 until the summer of 2004, we have conducted an empirical study of the development, launch and use of the Internet-based service provided by a paper machine producer, Metso Paper, to its customers. The customers are mills worldwide. The Internet-based service contains information about a critical component in the paper machine.

The purpose of this study is to explore the concept of value from customers as well as the service provider's point of view in this particular case study. For the sake of the purpose, Amit and Zott's [2] model of value creation sources in e-business have been customized for evaluating the sources of value in Metso Papers Internet-based service.

Based on the characteristics of our case and the choice of object under study the overall question posed in this paper is therefore:

- What changes are necessary when adopting Amit and Zott's [2] model of sources of value creation in ebusiness when evaluating the sources of value in Internet-based services?

The structure of this paper is as follows; first a presentation of the theoretical framework will be undertaken. Then, a presentation of the method of the study will be carried out, followed by a presentation of the case. In the theoretical framework an expanded model perspective is presented where we introduce the business-to-business perspective. After that, a section on value creation in e-business is presented followed by a presentation of this case business-tobusiness context and the consequences of changing object under study from e-business to complementary services. After the presentation of the case, results and analysis is presented, where the chapter is divided into two parts, before use and use of Internet-based service. Furthermore, the parts are subdivided according to the four sources of value creation in e-business; lock-in, complementarities, efficiency and novelty (adopted from Amit and Zott, [2]). The paper ends with conclusions and further studies. 


\section{Theoretical framework}

The theoretical framework is divided into three sections. First, an expanded model perspective, including the business-to-business perspective and the focus on Internet-based services, is introduced. Thereafter follows a section of research focusing on value creation in e-business where the business model [2] is presented. Finally, the consequences of the new business-to-business context and changing object under study are discussed.

\subsection{The business-to-business context - an expanded perspective}

In order to attract and keep customers on the market today, producing organizations not only need to provide good products, but should also provide additional services bringing customer-perceived added-value to the product. There are several advantages with customer support, also referred to as product support, Internet-based service, technical support or simply service. Manufacturers can achieve customer satisfaction and good long-term relationships. Moreover, customer support can provide a competitive advantage and play a role in increasing the success rate of new products [14]. Loomba [19] points out that after-sale customer service is becoming more vital for organizations to win orders and is also an important research priority. In order for firms to compete effectively in the market today, they need to re-evaluate their existing distribution and after-sales support channels, and make adjustments when necessary [25]. Armistead and Clark [3] state: "Good customer service and support ensure that the customer gets maximum value from the purchase." In addition, customer service is even more critical in electronic commerce (ecommerce) because customers and firm representatives do not meet face to face. Consequently, customers are interested in the usefulness of the product or the service, i.e. the value of the services and goods. The value is made up of the ability of the service to solve problems or satisfy needs that the customer might have [11].

To produce a competitive functional quality in the service process, it is essential to carefully plan the qualitygenerating resources - personnel, systems, technologies and physical resources, since the moments of truth between contact personnel and customers are a critical resource. Grönroos [16] emphasize that the service organization has to understand what their customers want. The organization needs to acquire information about the customers' needs and wishes. Grönroos [16] discusses how to structure a service organization and manage service processes so that the service provider becomes customer-oriented. According to him, the service system can be seen in a network of systems since firms cooperate to get competitive advantage. These networks make the service system model more complicated because the relationships between the parties in a network are often mutual. When the customer looks at the total service system it will be hard to judge where it went wrong if a problem would arise. Grönroos [16] states: "From a management point of view, it is essential to observe the existence of these networks of independent or affiliated service systems, and to realize the impact of one system on another and on the success of the total system" [16].

The focus of marketing for firms is shifting from the activity of attracting customers to activities with an emphasis to keep and take care of the existing ones [27]. Value is regarded as an important factor of relationship marketing and the ability for a firm to provide excellent value to its customers is an important strategy for competitive advantage. By adding more value to the core product, e.g. the quality of the product is improved or services are added, firms try to improve customer satisfaction and strengthen the bonds [27]. Porter [25] stresses the importance of the firm's relationships and interactions both internally and externally, the latter inter-organizationally with both customers and suppliers.

\subsection{Value creation in e-business}

E-commerce is growing in importance for both individuals and businesses leading to consequences for how firms compete. Creating value for customers that stands out of the competition has become vital for firms competing through e-commerce. Business models are created and used for the particular purpose to compete and create a competitive advantage. Therefore, business models are said to be critical for firms competing in e-commerce [3], [20], [32]. Turban et al. [31] define electronic commerce as: "the process of buying, selling, transferring, or exchanging products, services, and/or information via computer networks, including the Internet." A business model is defined as a method by which a firm builds and uses its resources to offer customers better value than the competition and making money doing so [1]. Wang [32] explains the combination of e-commerce and business models, i.e. an ebusiness model as: "a competition strategy for the marketplace and a structure of business processes for the entire electronic trade course..."

The network-based value creation model [2] provides a good foundation when trying to grasp some of the most important value creation sources of e-business because value creation spans firm and industry boundaries, something that is covered in the model. Previous attempts to understand value creation or superior performance has resulted in particular theoretical frameworks [17], for example, the value chain framework [25], [26] the creative destruction theory [29], the resource-based view of the firm [4], the strategic network theory [10] and transaction costs economics [33]. However, these theoretical frameworks do not focus on e-business in particular and fall short when trying to understand numerous potential sources of value creation. To the best of our knowledge, Amit and 
Zott's [2] business model is the first attempt to unify different theoretical frameworks as [25], [29], [33], [4]) and [10] in one single business model to understand value creation in e-business.

The main reference point of Amit and Zott's [2] business model is a particular firm, but it spans firm boundaries because it includes all the agents, even though they do not come from the same industry, through open networks based on the fixed and wireless Internet infrastructure of a particular transaction. In addition, virtual markets provide possibilities to extend products or services to incorporate complementary products, enhanced access to complementary resources and capabilities, innovative forms of collaboration between firms, which ultimately have an effect on how value can be created. Opportunities to create value may come from new ways of combining information, physical products and services as well as integration of resources and capabilities among partners. These characteristics are important to capture when analyzing virtual firms, where industry boundaries are difficult to draw. In this paper we adopt the value creation model [2] as our framework for analysis of a single case study [34] mainly because of three reasons. Metso Paper personnel mentioned three reasons as the driving forces behind the decision to develop the SymBelt Customer Center. The reasons were connected with a vision that the SCC would lower the costs for customers due to fewer breakdowns. Secondly, the SCC would improve information flows, both internally and externally. Finally, improved information flows were predicted to facilitate planning and reduce uncertainty for customers. All of these three reasons were also the underlying foundation behind [2] the value creation model for e-business, making it appropriate for use in this case study. Using the value creation model [2] will provide a good background to explore and explain the driving forces behind the development and the use of the SymBelt Customer Center from Metso Paper and some of its customers.

Amit and Zott [2] explore the theoretical foundations of value creation in e-business. The terms 'source of value creation' and 'value driver' that they use refer to any factor that enhances the total value created in e-business. Furthermore, the value is the sum of all values that can be appropriated by the participants in e-business transactions, regardless of whether it is the firm, the customer, or any other participant in the transaction who appropriates that value. They suggest a model with the purpose of showing the value creating potential in e-business firms. This model primarily consists of four dimensions, or four potential sources of value creation, that also are interrelated (figure 1):

- Lock-in

- Complementarities

- Efficiency

- Novelty

Amit and Zott's [2] definition of a business model is: "A business model depicts the content, structure, and governance of transactions designed so as to create value through the exploitation of business opportunities." The model of sources of value creation in e-business is supposed to be used as the unit of analysis because no single entrepreneurship or strategic management theory is sufficient in order to fully explain the value creation potential of e-business [2]. However, each single theory is helpful in the understanding of the value creation potential in ebusiness and is even more helpful when combined.

The business model that Amit and Zott [2] present is created from an analysis done from structured questionnaires with 59 e-businesses, 30 in the U.S. and 29 in Europe. The chosen organizations were business-to-consumer (B2C) firms, involved in transactions with individual customers. No business-to-business firms were included in the sample.

\section{Novelty}

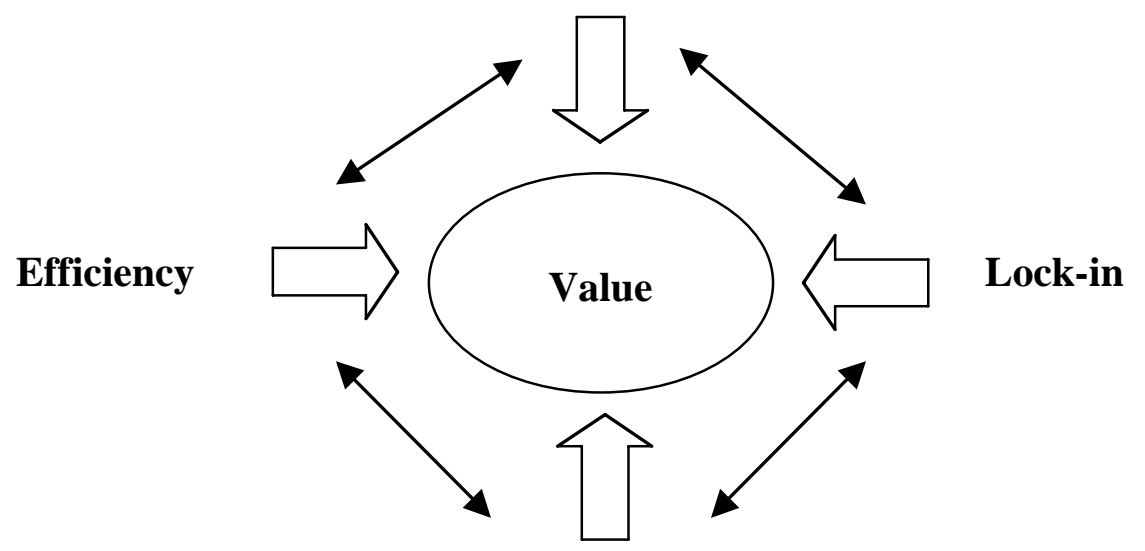

Complementarities

Figure 1: Sources of value creation in e-business 
Lock-in is one dimension that Amit and Zott [2] consider being a source for value creation potential in e-business. If firms possess the ability to make customers engaged in making repeat purchases, it will obviously be good for the profit of the firm. The study made by Amit and Zott [2] shows several ways in which customer retention can be enhanced, for instance loyalty programs rewarding repeat customers with special bonuses, firms can develop dominant design proprietary standards from business processes and trustful relationships can be built. Furthermore, their analyzed data shows that e-business enhance lock-in by enabling customers to customize products, services, or information to their individual needs in a variety of ways.

The other source proposed as a potential for value creation in e-business is complementarities, which are present whenever having a bundle of goods that together provides more value than the total value of having each of the goods separately. The data analysis suggests that e-businesses leverage the potential for value creation when offering the bundles of complementary services to their customers [2]. One example of complementarities is the object under study in this case study, i.e. the Internet-based service.

In e-business, efficiency can be gained through cuts in costs of transactions [2]: "the greater the transaction efficiency gains that are enabled by a particular e-business, the lower the costs and hence the more valuable it will be". Also efficiency can be improved by up-to-date information on the Internet.

The fourth and final dimension is novelty [2]. E-businesses also innovate in the way they do business, which is in the structuring of transactions. eBay, for example, that introduced customer-to-customer auctions on a large scale, and other firms that have created value by connecting previously unconnected parties, adopted innovative transaction methods and created entirely new markets.

\subsection{New context and different object under study}

The model by Amit and Zott's [2] is not completely flawless for this particular study. It is foremost due to the fact that our context is business-to-business and the object under study is an Internet-based service. However, Amit and Zott [2] put forward that the value driver categories identified in the analysis also should apply to B2B models, though with different weights of the four categories described above (figure 1).

The fact that the focus of this study lies on an Internet-based service and not e-business in general makes it necessary to make adjustments of Amit and Zott's model of value creation sources [2]. In the case of Metso Paper's Internet-based service, the SymBelt Customer Center, the service deal with one expensive and critical component of a paper machine that is not easily replaceable. This context is most likely different from a consumers view on an Internet-based service on for instance clothing. Complementarities are not a source in our study, as was the case in Amit and Zott's model of value creation sources [2], rather the object under study. We will study the evaluation of value of the Internet-based service, the SymBelt Customer Center.

\section{Method}

In order to accomplish the purpose of this study, which is to explore the concept of value from customers as well as the service provider's point of view of Metso Paper's Internet-based service, we have conducted a case study. This exploratory qualitative study was carried out using the case study method [34] to collect primary data. Case studies can involve either single or multiple cases and several levels of analysis [34], but this study involves one single case and several levels of analysis. The purpose of a case study is to describe, test theory or generate theory [12]. One of the disadvantages when building theories from case study research is that the theory can be very rich in detail, but be deficient in overall perspective. However, theory building from case study research is preferable when existing theory about the research area seems to be lacking, which was the situation in this case study.

Case studies in general and this study in particular have been conducted with the help of several data collection methods, i.e. archives, interviews, questionnaires and observations [34].

In this study archives were represented by documents provided by employees at Metso Paper, i.e. internal documentation and scanning of the website (www.metso.com). In the study 16 interviews have been carried out with customers (personnel at mills) of the SCC and employees at Metso Paper (table 1). Interviews with employees at Metso Paper Karlstad have been the project leader of the SCC development project, personnel at functions such as service, IT, and management. During the development, launch and use phases of the SymBelt Customer Center continuous contacts with the project leader has taken place. In addition, a number of meetings with employees at Metso Paper Karlstad were also held. In the year of 2003 a workshop was held between representatives from Metso Paper Karlstad and researchers involved in this study. At the beginning of 2004, the CEO of Metso Paper Karlstad was interviewed on his thoughts on the development and use of Internet-based services like the SymBelt Customer Center. Most interviews with employees at Metso Paper Karlstad and all interviews with customers have been recorded. 
The research study started in the spring of 2002 with examining some of Metso Paper's Swedish pilot customers' (a few selected customers involved in the development of the SCC) expectations of The SymBelt Customer Center. The study focused on a number of pilot customers through the implementation process and their usage of the SCC. Representatives for three Swedish pilot customers were participating in the study. Nine personal interviews have been conducted with respondents at the mills, before use and during use of the SCC. The interviews primarily contained questions about the pilot customers' expectations on and perceived value regarding the SymBelt Customer Center.

\begin{tabular}{|l|l|l|l|l|}
\hline Respondent & Company & Tasklassignment & Data acquisition & Point in time \\
\hline Customer & Stora Enso & Operations & 3 interviews & $2002,2003,2004$ \\
\hline Customer & Stora Enso & Maintenance & 3 interviews & $2002,2003,2004$ \\
\hline Customer & Assi Domän & Maintencance & 2 interviews & 2002,2003 \\
\hline Customer & Korsnäs & Maintenance & 1 interview & 2002 \\
\hline Employee & Metso Paper & Project leader & 3 interview, workshop & 2002,2003 \\
\hline Employee & Metso Paper & CEO & 1 interview & 2004 \\
\hline Employee & Metso Paper & IT manager & 1 interview, workshop & 2003 \\
\hline Employee & Metso Paper & Service manager & 1 interview & 2003 \\
\hline Employee & Metso Paper & Product manager & Workshop & 2003 \\
\hline Employee & Metso Paper & $\begin{array}{l}\text { Business Development } \\
\text { Manager }\end{array}$ & 1 interview & 2004 \\
\hline
\end{tabular}

Table 1: Data acquisition in the SymBelt Customer Center case study

The pilot customers started to test the SCC in the spring of 2003. At that time the pilot customers had used the SymBelt Customer Center for approximately one month. Their expectations of value issues on the SCC were followed up in interviews conducted in the summer of 2003. In 2004, when the pilot customers had used the SymBelt Customer Center for approximately a year, issues concerning value creation sources were once again in focus, but this time based on actual use of the SCC. The analysis of this study was carried out with the help of the value creation model [2].

\section{Presentation of the case}

For approximately two years an Internet-based service that the paper machine producer Metso Paper in Karlstad, Sweden, launched to their customers has been studied. The Internet-based service is called the SymBelt Customer Center (SCC) and the potential customers were personnel at mills in different countries around the world. Metso Paper is a global supplier of papermaking, tissue making, pulp making and board making lines. The company is a global market leader of paper and tissue making lines. It serves pulp, paper, tissue and board manufacturers throughout their processes - from pulp making to the wrapping of finished rolls. An increasing share of its business is comprised of aftermarket operations. Metso Paper's net sales in 2003 were EUR 1,651 million, which was 38\% of Metso Corporation's net sales. The business area employs approximately 9,000 people in 30 countries. The headquarter of Metso corporation is based in Finland.

At Metso Paper in Karlstad, one crucial component of a paper machine is produced, the SymBelt Shoe Press Roll. The press is a result of over ten years of continuous work and field experience. Some of the advantages with the SymBelt Shoe Press Roll are said to be that it increases the dryness levels out of the press, works at a high speed and give a high quality paper at low power consumption and costs. Today, more than 100 customers worldwide have the SymBelt Shoe Press Roll in their paper machines.

The SymBelt Customer Center is an Internet-based service center that helps the customer to optimize the SymBelt installation and use. SCC supports Metso Paper's services and makes it possible for the customer to get improved control of the SymBelt Shoe Press Roll. It is a communication channel that is open 24 hours a day, 7 days a week, and 365 days a year. The SymBelt Customer Center includes functions where activities are registered. The customers can report disturbances and also have access to the status of reported cases. In the SymBelt Customer Center, planned services and service history is presented. In addition, all documentation on the mill's SymBelt Shoe Press Roll is available, as well as an updated contact list of employees at Metso Paper. Two other functions of the SCC are an FAQ section where the customers own questions can be raised and a forum where SymBelt Shoe Press Roll questions can be discussed.

The idea to develop The SymBelt Customer Center was introduced by the Business Development Manager at Metso Paper Karlstad in the year of 2000. At that time e-business was almost a necessity and as a result discussions within the Metso Paper took place on how to use and gain benefits of e-business. There were several reasons for the choice of an Internet-based service of the SymBelt Shoe Press Roll. One of the reasons of choosing to develop the SCC is that the product is unique in the sense that it is not replaceable with a similar product in case of a breakdown. 
Therefore, it is important for customers that it is in good shape to prevent breakdowns to occur. In addition, the SymBelt Shoe Press Roll is a relatively new product produced at Metso Paper Karlstad. Furthermore, it is a major investment for the customers. Taking these factors together the SymBelt Customer Center was initiated in order to provide the customers with increased control and secure the operations of the SymBelt Shoe Press Roll. The idea was to build an Internet-based service that would improve Metso Paper's service and feedback for the customers. This was predicted to lead to shorter stops after breakdowns and less time to get back to normal production levels.

With the help of an internal database at Metso Paper Karlstad, that keeps track of installations of the SymBelt Shoe Press Roll, it is possible to see if similar problems has previously occurred and easier solve often critical, problems. The Service Manager of the SCC-project at Metso Paper states that the SCC is not supposed to be used only when problems occur. Although this might be the primary function of the Internet-based service, a complementarily function, like downloading drawings or keep track of the history of certain matters, are examples of important functions of the SymBelt Customer Center.

When developing The SymBelt Customer Center, Metso Paper involved a number of selected customers (pilot customers) in the development process. The reason for this, according to Metso Paper, is that customers are the main future users of the Internet-based service and their opinions about issues like the SCC's contents, quality and usability are therefore extremely relevant for the success of the SCC.

\section{Results and analysis}

This section is divided into two parts, before use of the Internet-based service (the SymBelt Customer Center) and actual use. Furthermore, the two parts are subdivided according to the four dimensions in figure 1: lock-in, complementarities, efficiency and novelty [2]. We take a standpoint from the perceptions of the SCC from both the supplier and the customers view. Hence, we suggest the importance of a relationship perspective when studying value of an Internet-based service. Therefore, the suggested expanded perspective including the dimension of a business-to-business context, presented in the theoretical framework, is crucial to bear in mind in the presentation of the results and analysis below.

\subsection{Before use}

Davis et al. [8] discuss the importance of finding new methods for evaluation of acceptability of systems as early as possible in the development of information systems. This could better help to decide if the system needs to be changed and decrease the risks of developing a system that is not going to be used. Davis et al. [8] state that the most vital problem, when assessing user acceptance of IS in the early stages of development, is the difficulty to give users a clear picture of features and functions of the new system. From the in-depth interviews an overall positive attitude towards the future Internet-based service was evident. Possible explanations could be that users perceive the Internet-based service to be valuable or that users' involvement in the development process has influenced users' thoughts and feelings in a positive manner.

The overall picture in our study was that pilot customers were satisfied with the opportunities to share opinions and concerns regarding the upcoming Internet-based service. Pilot customers concerns of missing features and functions in early presentations of the upcoming Internet-based service were taken into consideration and later developed and implemented into the SymBelt Customer Center. Customer involvement was also of high priority by the Business Development Manager who exposed the following:

"Some customers were involved from the start of the project. They were involved in the initial discussions about if this type of Internet-based service could create value for them. They were also involved as pilot customers where they could try the service and give feedback of what to change. Certain chosen pilot customers were involved from the start to the end of the project."

Lock-in

Regarding the lock-in dimension, the B2B context and the nature of the product the Internet-based service support are crucial to consider. The amount of time that the customers work with the SymBelt Shoe Press Roll varies a lot over time. Sometimes the work with the shoe press roll is very intense followed by periods where no work at all is made. The respondents often contact Metso Paper Karlstad when there is a problem with the SymBelt Shoe Press Roll that cannot be solved by in-house personnel. When it comes to operational maintenance of the paper machine regarding the SymBelt Shoe Press Roll, it is quite natural for customers to turn to the paper machine producer Metso Paper if they cannot solve the problems internally. The "create-capture-keep" strategy [21] will make customers to the supplier unwilling to change to another supplier because of switching costs.

Amit and Zott [2] discuss interdependencies between all of the dimensions of the business model. One example is the possibility to become a first mover, which, if successful, can lead to both novelty and lock-in. Metso Paper confirmed this since one of the objectives was to create a unique and valuable service and thereby strengthen the relationship with the customers. In addition, this unique service would also create a competitive advantage because 
no other competitor had something similar when the project started. The pilot customers also emphasized that they had very strong and long-term relationships with employees at Metso Paper.

\section{Complementarities - the object under study}

One of the most important reasons to build the SCC around the SymBelt Shoe Press Roll was that the SymBelt Shoe Press Roll is a crucial component in the paper machine. The SymBelt Shoe Press Roll is critical, in contrast to many other parts of the paper machine, because the component is not easily replaceable due the very high price and therefore is not possible to hold in inventory. Because of the characteristic of the SymBelt Shoe Press Roll it is essential that the paper machine is working to its full potential and when problems occur it is possible to repair the machine as quickly as possible. The main purpose of the project was to provide the customer with an increased level of operation of the paper machine. From the paper machine producer's Metso Paper's perspective, the overall purpose of investing in this type of Internet-based service was to increase revenue and if possible reduce costs. In addition, the SCC should be a marketing tool to sell more services on the shoe press roll and therefore, the firm could increase its incomes. The customers were looking forward to an Internet-based service that would give them easy access to personnel at Metso Paper and also to documentation of the SymBelt Shoe Press Roll.

\section{Efficiency}

The Business Development Manager compared the SymBelt Customer Center with the display in a car telling you when it is time for service. In a multinational company like Metso Paper it is hard to uphold a good communication with all customers around the world. As it is difficult to visit the customer face-to-face the SymBelt Customer Center was thought to be a good complement. One customer says that it is hard to know how the SymBelt Customer Center is going to be used since it is not yet completed. He means that one great advantage with the SymBelt Customer Center is that the history of matters and questions regarding the SymBelt Shoe Press Roll is documented, which is different from when the telephone is used. He states: "It is important to know what has been done and when".

The SymBelt Customer Center will lead to a more convenient way of working because of increased efficiency, one customer state. Today it can take several phone calls before he get hold of the person who has got the information he needs. He thinks that it is a bit tricky to get information from personnel in large organizations where the competences are geographically dispersed. The customer states that often personnel at Metso Paper Karlstad only receives his question and then asks to get back to him since they in turn have to collect information. Through the SymBelt Customer Center the customer expects to get into the right channels in order to reach the right knowledge resources. In that way, he sees the SymBelt Customer Center as a funnel. "Two-way communication" is a term that the customer uses to emphasize the importance for both the customer and supplier organizations to talk to the person with the right competence. Another customer thinks that it is nicer to talk to a person than to use the computer to communicate. Many times, he means, it is hard to explain what you mean in writing. In addition, the receiver might perceive the text in another way than the writer meant. He expresses that one risk with SymBelt Customer Center could be that the personal contact with personnel at Metso Paper Karlstad could be lost. The same customer does not think that the SymBelt Customer Center will affect his work, as the personnel at Metso Paper are reachable at his working hours, either by e-mail or by phone. Perhaps some communication will be conducted through the SymBelt Customer Center. However, he thinks that; "90 percent of what is put forward as a question in the SymBelt Customer Center will end with a phone call anyway".

\section{Novelty}

The Business Development Manager stated that one other reason to invest in this type of Internet-based service was to create a competitive advantage in comparison with competitors service offers. One of the initial ideas of the SymBelt Customer Center was that it would contain a user forum. This forum would be innovative and unique since nothing similar had been available ever before. Pilot customers also expressed interest in this type of service where knowledge of the SymBelt Shoe Press Roll could be passed on between customers easier than before. The same idea of sharing knowledge between employees within Metso Paper was also one possible advantage of the SCC mentioned in the interviews. The IT Manager described in the interviews how it is suppose to work: "When someone uploads information to the database this information is then accessible for other people in the Metso Corporation." However, regarding whether it is really working as supposed, i.e. communication between customers, the Service Manager at Metso Paper states: "That's our objective, but perhaps we are not there yet. We have to remember that this type of service is a relatively new phenomenon."

Three respondents express that they only think that the SymBelt Customer Center is a beginning to something much bigger, which is an Internet-based service that covers all parts of the paper machine delivered by Metso. One of them states that he thinks that it will take a number of years before that could be a fact.

\subsection{Use}

Orlikowski [23] and Zeithaml [35] state that it is crucial to study the usage of an information system, such as an Internet-based service, as the users integrate the IS into their daily practices. Until the information system is used it is impossible for the user to form a judgment about the quality, or excellence of the service [35]. The study shows that the pilot customers', during the approximately one year of usage of the SymBelt Customer Center, have used the Internet-based service on only a few occasions. The respondents mean that the Internet-bases services could be valuable when there are problems with the shoe press roll. However, not many problems have occurred at the mills 
during the time of study. The pilot customers' representatives state that it is good that they do not need to use the SymBelt Customer Center since it is an evidence of that the SymBelt Shoe Press Roll works well.

Lock-in

A dimension that Amit and Zott [2] put forward as being a source for value creation in e-businesses is lock-in. When firms possess the ability to make customers do repeat purchases it will be good for the profit of the firm. In that way trustful relationships can also be built. In the case of Metso Paper and its customers, stakeholders in both firms imply that they have strong relationships with personnel at the other firm. The nature of the product invested in, the SymBelt Shoe Press Roll, lead to repeat purchases of spare parts and services from the paper machine supplier Metso Paper. In that sense, the nature of the product in itself leads to what Amit and Zott label lock-in.

Complementarities - the object under study

The SymBelt Customer Center is an Internet-based service that is a type of complementarities. Metso Paper's initial idea with the Internet-based service was, in part, to improve security and control for the customers on a shoe press roll and thereby reduce costly breakdowns and provide better service when breakdowns occur. In the long run this would then influence customer feelings of trust and reliability of the paper machine producer and thereby strengthen the relationship [21].

The SymBelt Customer Center can be said to be an Internet-based service that supports both the product SymBelt Shoe Press Roll and Metso Paper's services surrounding the product. The SCC so far supports only one part of the paper machine. Amit and Zott's [2] data analysis suggests that e-businesses leverage the potential for value creation when offering the bundles of complementary services to their customers. The pilot customers' would appreciate if the SymBelt Customer Center was developed to include all parts of the paper machine, not only the SymBelt Shoe Press Roll. They mean that such an Internet-based service would be more valuable to them and then they would use it more frequently. The personnel at Metso Paper state that they would have liked the customers to use the SCC to a higher degree. However, to date Metso Paper does not plan to develop the Internet-based service further. The Service Manager of shoe press rolls states that it is expensive to develop e-business solutions and today the firm focuses on other areas.

\section{Efficiency}

Amit and Zott [2] mean that efficiency can be gained through cuts in costs of transactions in e-business. Moreover, efficiency can be improved by up-to-date information on the Internet. After one year of infrequent use of the SCC, some functions are perceived to be valuable to the pilot customers. The easy access to drawings is perceived to be the most valuable function to date. Training material is also perceived to be valuable. Besides those functions, routines are run in the same way as before the launch of the Internet-based service, which is primarily over the phone or e-mail. Neither has the personnel at Metso Paper noticed any changes in the customers' contact behavior.

The three interviewed customers state that they hope that they will use the SymBelt Customer Center very seldom as they will not use it when the SymBelt Shoe Press Roll works well. It is when they have got some kind of problem or wants to rebuild something around the SymBelt Shoe Press Roll that they will use the Internet-based service. One customer says that normally he does not look at drawings over the SymBelt Shoe Press Roll and explains: "You do not care about a machine that works".

\section{Novelty}

The fourth and final dimension that Amit and Zott [2] suggest is novelty. Most of the transactions that can be done in the SymBelt Customer Center can also be made through more traditional means like telephone or fax. A lot of the interaction between the personnel at the paper machine supplier and its customers is also handled through electronic mail. One novelty dimension, through which value can be created, is to connect previously unconnected parties in the SymBelt Customer Center. In the Internet-based service, there is a possibility to communicate between customers in a forum. This possibility had, after one year of access to the SymBelt Customer Center, not been used at all. However, the customers say that they do communicate issues they have on the paper machine with other customers, often over the telephone. One customer stated that other customers could give better information about certain problems than Metso Paper can. The same customer said that this could be due to the fact that knowledge is gained through the operations of the paper machine. As a result, of the customers not using the forum, Metso Paper cannot take part of the questions the customers share between each other. If Metso Paper had access to this information, they could perhaps understand more about the issues raised at the customers' mills, and even solutions to problems.

\section{Conclusions and further studies}

\subsection{Conclusions}

A starting point in this study is that there are strong personal relationships between the customers and the supplier. We therefore propose that a relationship perspective, including stakeholders' perceptions regarding the value of the Internet-based service at both the supplier and the customer, is necessary to take in order to understand sources of value perceptions in the Internet-based service. 
In the study, where data was gathered in two phases - pre-use and use - we utilized four dimensions: lock-in, complementarities, efficiency and novelty (figure 1). The study is conducted based on user's perceptions on Metso Paper's Internet-based service named the SymBelt Customer Center. The study shows that the pilot customers' representatives, during the approximately one year of use of the SymBelt Customer Center, have used the Internetbased service on few occasions. The respondents mean that the Internet-based services could be valuable when there are problems with the shoe press. However, not many problems have occurred at the mills during the time of the study. The pilot customers' representatives state that it is good that they do not need to use the SymBelt Customer Service since it is a sign of that the SymBelt Shoe Press Roll works fine. So far, Metso Paper's main aim of the SymBelt Customer Center, which was to provide the customers with improved possibilities to operate the paper machine, does not seem to have been fulfilled. Some functions in the Internet-based service seem to be more relevant to the customers than others. The customers would also like the SCC to include the complete paper machine rather than only on the SymBelt Shoe Press Roll. In this study, the SymBelt Customer Center project, that started at a point in time when it was more or less a must to actively engage in e-commerce, did not get very much support when the company needed to cut costs and improve revenue. Although customers of the SymBelt Customer Center were very pleased with the outcome of the project, the project management decided based on the low usage to stop further development of the SymBelt Customer Center.

Drawing from this study, we suggest that the nature of the core product (expensive to buy, used frequently, difficult to replace, costly when breakdowns occurs etc.) influence and is being influenced by the Internet-based service when it comes to value. Therefore, when studying evaluation of sources of value in the Internet-based service in a businessto-business context the nature of the core product must be taken into account. Complementarities, suggested by Amit and Zott [2], as a source of value creation are proposed in this paper to be replaced by the nature of the core product. The reason why nature of the core product is important was exposed several times during the study.

Another conclusion that can be drawn from this study is that the low use of the SymBelt Customer Center affects the efficiency and therefore the perceived value of the SCC. As the customers do not use it to a high degree, efficiency levels at the supplier side are not improved. Regarding the novelty dimension and the way transactions is structured in e-business, interactions between the supplier firm and the pilot customers have not changed since the SCC was introduced. As for the lock-in dimension, the actual product in itself, not the complementing Internet-based service, seems to be very relevant for repeat purchases of services and the creation of close relationships between the customer and the supplier. The most important findings from the study can be found in table 2 .

\begin{tabular}{|l|l|l|}
\hline Lock-in & Pre-use & Use \\
\hline Complementarities & - SCC will create lock-in. & $\begin{array}{l}\text { - Metso argued for the suitability } \\
\text { cause lock-in. }\end{array}$ \\
\hline $\begin{array}{l}\text { of an Internet-based service } \\
\text { solution because of the nature } \\
\text { of the core product. }\end{array}$ & $\begin{array}{l}\text { - Too isolated and small in relation } \\
\text { to the whole paper machine in } \\
\text { order to be valuable. }\end{array}$ \\
\hline Efficiency & $\begin{array}{l}\text { - Increase revenue and if } \\
\text { possible reduce costs. }\end{array}$ & $\begin{array}{l}\text { - No signs of increased revenue } \\
\text { and reduced costs. } \\
- \text { No changes in customer } \\
\text { behavior. }\end{array}$ \\
\hline Novelty & $\begin{array}{l}- \text { Connect previously } \\
\text { unconnected parties through } \\
\text { the SymBelt Customer Center. }\end{array}$ & $\begin{array}{l}\text { - No success in connecting } \\
\text { previously unconnected parties } \\
\text { through the SymBelt Customer } \\
\text { Center. }\end{array}$ \\
\hline
\end{tabular}

Table 2: The most important findings from the study.

This study has shown that the nature of the core product, the SymBelt Shoe Press Roll, is relevant in this specific business-to-business context. We therefore suggest a modification of Amit and Zott's [2] business model to include nature of the core product, instead of complementarities, when evaluating an Internet-based service in a business-tobusiness context. In this study it is evident that the SymBelt Shoe Press Roll is extremely important for customers of Metso Paper and their perceptions of value regarding the SymBelt Customer Center. Another intention with the SymBelt Customer Center was to reduce the risk of breakdowns and expand failure support. Taken together, this was supposed to lead to improved operational outcome of the SymBelt Shoe Press Roll. So far, these outcomes have not proven to be the case for either the customers or the supplier. 


\subsection{Further studies}

It would have been interesting to conduct the study over a longer time frame. Since customers in the study did not have much problems with the paper machine in general and the SymBelt Shoe Press Roll in particular customers did not turn to the SymBelt Customer Center when in need for help, for obvious reasons. Customers did not need any help.

Moreover, as Fichman [13] suggests in his study there are many factors influencing adoption, diffusion and assimilation. When looking back at the Metso Paper case we can conclude that although the newly developed system, which was developed in close relation to the users and their needs, did not turn out to be a success. The result of the development process turned out to be an Internet-based service that was fairly easy to use and was initially perceived as valuable by the users. However, more than a year after the launch, the SymBelt Customer Center has been adopted to a low degree by the users.

Relevant as an explanation of the low degree of adoption in the Metso Paper case is defined as the two-part adoption decision [13]. Many IT innovations involve a two-part adoption process, where a more formal adoption decision is followed by local decisions. In the Metso Paper case this is relevant at the customer side as well as at the supplier side. If we start to look at the supplier side this is apparent because Metso Paper Karlstad was the one developing the System. Although Metso Paper Karlstad was the one initiating the process from the start it soon became apparent that their interest in supporting the development of the system was decreasing. Even if the customers were pleased with the Internet-based service it is not economically reasonable, from a business management point of view, to give a high priority to further development of a system with low customer usage. This change of focus will consequently have an effect on making customers to adopt the system.

Likewise, the two-part adoption decision can also explain some of the low degree of usage among customers. If management in the customer firms had declared the importance of using the system it would probably have been more used. However, some of the intended users tend to have rather strong influence of whether to use the system or not so it is difficult to say whether it would have changed the situation that much. Nevertheless, more attention on individual technology acceptance is necessary in order to fully understand the adoption process as well as more thoroughly study the two-part adoption decision [13].

\section{References}

[1] A. Afuah, and C.L. Tucci. Internet Business Models and Strategies: Text and Cases, McGraw-Hill, 2001.

[2] R. Amit, and C. Zott. Value creation in e-business. Strategic Management Journal, Vol. 22, No. 6/7, pp. 493-520, 2001.

[3] C.G. Armistead, and G. Clark. Customer Service and Support, Longman Group, London, UK, 1992.

[4] J.S. Barney. Firm Resources and Sustained Competitive Advantage. Journal of Management, Vol. 17, No. 1, pp. 99-120, 1991.

[5] G-W. Bock, R.W. Zmud, Y-G. Kim, and J-N. Lee. Behavioral intention formation in knowledge sharing: Examining the roles of extrinsic motivators, social-psychological forces, and organizational climate, MIS Quarterly, Vol. 29, No. 1, pp. 87-111, 2005.

[6] T. Brown. Using norms to improve the interpretation of service quality measures, The Journal of Services Marketing, Vol. 11, No. 1, pp. 66-80, 1997.

[7] J-L. Chandon, P-Y. Leo, and J. Phillipe. Service encounter dimensions - a dyadic perspective: Measuring the dimensions of service encounters as perceived by customers and personnel, International Journal of Service Industry Management, Vol. 8, No. 1, pp. 65-86, 1997.

[8] F.D. Davis, P. Bagozzi, and P.R. Warshaw. User Acceptance of Computer Technology: A Comparison of Two Theoretical Models, Management Science, Vol. 35, No. 8, pp. 982-1003, 1989.

[9] K. de Ruyter, M. Wetzels, and M. Kleijnen. Customer adoption of e-service: an experimental study, International Journal of Service Industry Management, Vol. 12, No. 2, pp. 184-207, 2001.

[10] J. Dyer, and H. Singh. The relational view: cooperative strategy and sources of interorganizational competitive advantage. Academy of Management Review, Vol. 23, No. 4, pp. 660-679, 1998.

[11] P. Echeverri, and E. Edvardsson. Marknadsföring i tjänsteekonomin. Studentlitteratur, Lund, 2002.

[12] K.M. Eisenhardt. Building Theories from Case Study Research, Academy of Management Review, Vol. 14 , No. 4, pp. 532-550, 1989.

[13] R.G. Fichman. The diffusion and assimilation of information technology innovations. In Zmud, R.W. (ed). Framing the domains of IT management: Projecting the future through the past. Pinnaflex, Cincinnati, 2000.

[14] K. Goffin, and C. New. Customer support and new product development - An exploratory study, International Journal of Operations \& Production Management, Vol. 21, No. 3, pp. 275-301, 2001.

[15] D.L. Goodhue. Understanding user evaluations of information systems, Management Science, Vol. 41, No. 12, pp. 1827-1844, 1995.

[16] C. Grönroos. Service Management and Marketing - A Customer Relationship Management Approach, John Wiley and Sons, Ltd., Chichester, UK, 2000.

[17] R. Hackney, J. Burn, and A. Salazar. Strategies for value creation in electronic markets: towards a framework for managing evolutionary change. Journal of Strategic Information Systems, Vol. 13, pp. 91-103, 2004. 
[18] P.J. Hu, P.Y.K. Chau, O.R. Liu Sheng, and K.Y. Tam. Examining the Technology Acceptance Model Using Physician Acceptance of Telemedicine Technology, Journal of Management Information Systems. Vol. 16, No. 2, pp. 91-112, 1999.

[19] A.P.S. Loomba. Linkages between product distribution and service support functions, International Journal of Physical Distribution \& Logistics Management, Vol. 26, No. 4, pp. 4-22, 1996.

[20] J. Magretta. Why Business Models Matter. Harvard Business Review, May, 2002.

[21] F.J. Mata, W.L. Fuerst, and J. B. Barney. Information technology and sustained competitive advantage: A resource-based analysis. MIS Quarterly, Vol. 19, No. 4, pp. 487-505, 1995.

[22] Metso (2004, April). Available: www.metso.com

[23] W.J. Orlikowski. Using Technology and Constituting Structures: A Practice Lens for Studying Technology in Organizations, Organization Science, Vol. 11, No. 4, pp. 404-428, 2000.

[24] G. Philip, and S-A. Hazlett. Evaluating the service quality of information services using a new 'P-C-P' attributes model, International Journal of Quality and Reliability Management, Vol. 18, No. 9, pp. 900-916, 2001.

[25] M.E. Porter. Competitive advantage: Creating and Sustaining Superior Performance. Free Press: New York, 1985.

[26] M.E. Porter. Towards a dynamic theory of strategy. Strategic Management Journal, 12, pp. 95-119, 1991.

[27] A. Ravald and C. Grönroos. The value concept and relationship marketing, European Journal of Marketing, Vol. 30, No. 2, pp. 19-30, 1996.

[28] G. Ray, W.A. Muhanna and J.B. Barney. Information technology and the performance of the customer service process: A resource-based analysis, MIS Quarterly, Vol. 29, No. 4, pp. 625-652, 2005.

[29] J.A. Schumpeter. Business Cycles: A theoretical and Statistical Analysis of the Capitalist Process. Harper: New York, 1942.

[30] S. Smithson, and R. Hirschheim. Analysing information systems evaluation: another look at an old problem, European Journal of Information Systems, Vol. 7, No. 3, pp. 158-174, 1998.

[31] E. Turban, D. King, D. Viehland, and J. Lee. Electronic Commerce - A Managerial Perspective. Pearson, Prentice Hall, 2006.

[32] S. Wang. Designing information systems for electronic commerce, Industrial Management \& Data Systems, Vol. 101, No. 6, pp. 304-314, 2001.

[33] O.E. Williamson. Market and Hierarchies, Analysis and Antitrust Implications: A Study in the Economics of Internal Organization. Free Press: New York, 1975.

[34] R. Yin. Case study research: Design and methods (2nd ed.) Thousand Oaks, CA: Sage Publishing, 1994.

[35] V.A. Zeithaml. Consumer perceptions of price, quality and value: a means-end model and synthesis of evidence, Journal of Marketing, Vol. 52, No. 3, pp. 2-21, 1988. 